\title{
Gauging The Hospitality Industry's Awareness and Commitment to Sustainability Practices: The Case of the Hospitality Industry in Muscat
}

Robyn Byrne
$\begin{gathered}\text { US Fulbright Fellow, 2010-2011 } \\ \text { byrne.robyn10@gmail.com }\end{gathered}$

\author{
Mohamed Abdul-Ghani \\ Assistant Professor \\ Tourism Department \\ College of Arts and Social Sciences \\ Sultan Qaboos University \\ drghani@squ.edu.om
}




\title{
Gauging The Hospitality Industry's Awareness and Commitment to Sustainability Practices: The Case of the Hospitality Industry in Muscat
}

\author{
Robyn Byrne* and Mohamed Abdul-Ghani
}

Abstract:

Oman is an emerging destination for green tourism, its slogan "beauty has an address", illuminates its attempt to brand itself as a destination for unique, cultural and environmental attractions. Oman's heritage is promoted along-side its natural beauty.

As the hospitality sector in the capital city "Muscat" plans to expand and scale up its demographic to attract more high-end tourists as well as the overall volume of tourists it welcomes, this study aims (1) to explore to what degree hotels in the capital city "Muscat" recognizes the environmental impacts of their economic choices, (2) to determine which of the numerous environmental considerations are most widely adopted, and finally, (3) to highlight some perspectives from policy makers and major tourism stakeholders in Oman about current sustainability trends and future goals regarding environmental management.

While the Sultanate has conducted a number of government studies of general tourism statistics, more effort is being exerted to ambitiously bring international tourists 'attention to visit Oman. Given the paucity of literature on tourism in Oman, and Omani government's commitment to a sustainable path of development, this study seeks to supplement the existing work on "green" and "environmentally conscious" tourism by focusing on this country of great and ambitious sustainable tourism development plans with applications on its capital city "Muscat" growing hospitality industry.

Keywords: Sustainability, Hospitality Industry, Green Practices, Sultanate of Oman

\section{قياس الوعي في صناعة الضيافة ومدى الالتزام بممارسات الاستدامةة: دراسة حالة صناعة الضيافة في مسقط}

روبين بيرن

الملخص:

تُعتبر سلطنة عُمان وجهة ناشئة للسياحة الخضراء، رافعة شعار "للجمال عنوان" وهو شعار خاص بالسلطنة مميز لها ومعبر عنها كعلامة

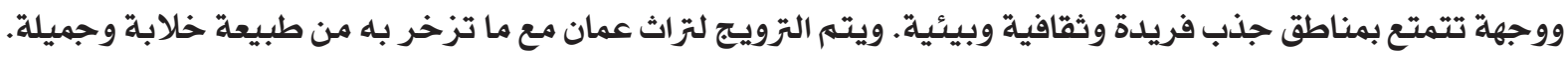

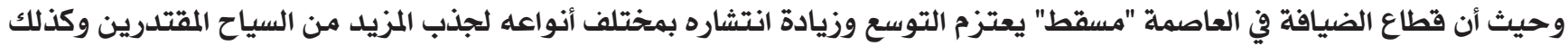

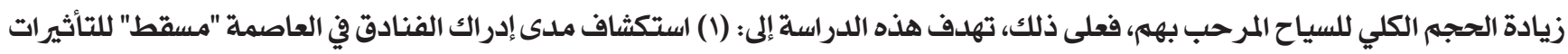
البيئية لاختيار اتهم الاقتصاديلة و (r) تحديد أي من الاعتبارات البيئية العديدة يتهم استخدامها على نطاق واسع وأخيراً (r) تسليط الضوء على بعض وجهات نظر صانعي السياسات وأصحاب المصلحة الرئيسين في مجال السياحة في عُمان حول اتجاهات الاستداملة الحالية والأهداف المستقبلية فيما يتعلق بالإدارة البيئية.

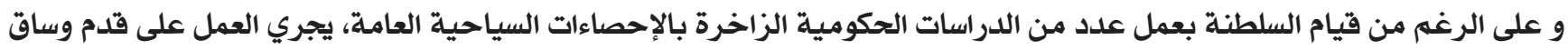

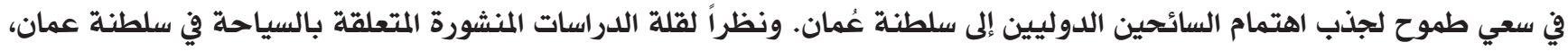

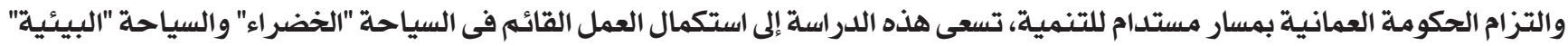
من خلال التزكيز على هذا البلد الذي تتوفر به خطط طموحة لتحقيق التنمية السياحية المستدامة وتطبيقاتها على صناعة الضيافيافة 


\section{Introduction}

"Green" has become a trend in environmental management of the hospitality industry and much effort has been spent to define and quantify its acceptance and implementation. Many of the largest international hotel chains include an environmental focus within their corporate social responsibility statements and promote their standards in publicly available environmental management audits. Sustainability in hospitality is sensitive to interpretation as represented by the lack of an industry-wide standard definition. However several common goals stood out through the review of related literature: (1) tourism should respect the economic well-being and socio-cultural conditions of local communities; (2) tourism should respect and operate within the natural carrying capacity of the environment; (3) tourism enterprises must not simply respect these limitations but lower their impact overall; and finally, (4) the tourism experience should be enjoyable and meaningful to the guest within these parameters (Beioley, 1995).

Within the global hospitality sector there are numerous certifications and standards for hotels to follow. Numerous audits and independent studies have been made of the environmental standards throughout Europe including Great Britain, and Australia, New Zealand. Indeed the promotion of eco-friendly standards has become so popular that concern is growing by customers overwhelmed by the various labels (Ellis, 2008). Further, the number of green certification systems has caused some observers to demand intragovernmental attention of the various accreditation systems and their relative merit.

This study focused on the supply-side aspects of green hospitality, demand side issues such as customer satisfaction and ethical consumers, while important to the topic are outside the scope of the study. It is worth mentioning, however that sources (Stabler and Goodall, 1997; Climpson, 2008) reported a higher willingness-to-pay phenomena for those activities marketed as green or environmentally sensitive. Such a trend should be considered by local professionals as an incentive to adopt sustainable practices as well as a future source of study and evaluation in the Gulf Cooperation Council (GCC) region.

\section{Background}

Oman is a young country of tremendous potential growth. Celebrating its 40th National Day in 2010, the Sultanate of Oman has developed rapidly thanks in large part to extensive petroleum and natural gas resources as well as stable political leadership. Oman is a home to just 3 million people, of which $20 \%$ are non-nationals. As it looks ahead however, Oman has placed great emphasis on the needs to diversify its economy to create a sustainable future. Much emphasis in its Vision 2020 - the Sultanate's plan for future economic and social development- has been given to the development and growth of the tourism industry. Aware of its natural beauty but finite resources, the Ministry of Tourism has projected "tourism will facilitate economic diversification, preservation of cultural integrity and protection of the environment of the Sultanate of Oman." (MOT, 2010) Sustainability has been incorporated into the mission of the Ministry of Tourism as well as OMRAN, the Sultanate's publicly owned tourism development and investment company. "We respect our nation's environment and wildlife, never destroying but always building in harmony." (OMRAN, 2010) Sustainable tourism management includes considerations for the local economy, culture and the environment; while Oman has made strides in all of these areas, special consideration should be paid to the environment as it has become tenet of marketing and management policies globally. While hosting of the 4th International Conference on Responsible Tourism in Destinations, the Sultanate has publicized its adherence to the trend of Responsible and Environmental Management in tourism and hospitality. Tourism and related travel accounted for $7.9 \%$ of GDP in 2010 and is expected to increase its share to $9.2 \%$ by 2020. (WTTC, 2010). Tourism and travel in Oman was responsible for $7.8 \%$ of total employment in 2010 and is expected to represent 1 in every 10 jobs by 2020. Growth per annum is expected to average $5.6 \%$ over the next decade. Further, tourism received 102 million USD or $1.3 \%$ of total government investment in 2010.

Oman has two commercial airports; the main terminal in Muscat, and a second in the southern city of Salalah. A long-range plan will bring the capacity of the Muscat airport from the current 5.7 million annual travelers to 12 million in 2014 and ultimately 48 million by 2050 . This enormous increase capacity has equally impressive and far-reaching implication for the hospitality and tourism industry in Oman (Oman Airports, 2010).

In 2008, Oman accommodated 1.7 million tourists, 1 million of whom visited the capital city of Muscat. Muscat boasts a large number of hotels ranging from resorts to limited service properties aimed at domestic, regional, and international tourists. Muscat con- 
tains 8 five-star properties reflecting the Sultanate's desire to attract larger numbers of high-end and corporate tourists. The scale is also heavy weighted to include more than 20 two-star hotels and 35 one-star accommodations largely catering to local and regional tourists from the neighboring GCC countries. These establishments tend to be located farther from the city's center. Subsequent studies should focus more attention on the low-end hotels as they are more likely to be locally owned sole-proprietorships, and less likely to benefit from the economies of scale which allow large, franchised chains to adopt otherwise expensive technologies (Hobson and Stephen, 2010). One-star hotels in Muscat averages 30 rooms per property, four-star and five-star hotels averaged 169 rooms per property. Further, many five-, four- and some threestar hotels are franchised or contract managed by major international hotel corporations which maintain corporate standards including environmental measures.

While the Sultanate has conducted a number of government studies of general tourism statistics, more effort is being exerted to ambitiously bring international tourists 'attention to visit Oman. Given the paucity of literature on tourism in Oman, and Omani government's commitment to a sustainable path of development, this study seeks to supplement the existing work on "green" and "environmentally conscious" tourism by focusing on this country of great and ambitious sustainable tourism development plans with applications on its capital city "Muscat" growing hospitality industry.

\section{Aim of the study}

Oman is an emerging destination for green tourism, its slogan "beauty has an address", illuminates its attempt to brand itself as a destination for unique, cultural and environmental attractions. Oman's heritage is promoted along-side its natural beauty.

As the hospitality sector in the capital city "Muscat" plans to expand and scale up its demographic to attract more high-end tourists as well as the overall volume of tourists it welcomes, this study aims (1) to explore to what degree hotels in the capital city "Muscat" recognizes the environmental impacts of their economic choices, (2) to determine which of the numerous environmental considerations are most widely adopted, and finally, (3) to highlight some perspectives from policy makers and major tourism stakeholders in Oman about current sustainability trends and future goals regarding environmental management.

\section{Literature review}

A great deal of the work surveyed consisted of industry publications, especially those newsletters and websites which seemed intended for consumption by hospitality professionals. Few of the sources consulted appeared to be intended for general consumers or for academic study. A general observation by the researchers was that few available publications included evaluative measures; rather they presented a series of best practices and associated means for achieving rather than evaluating those green programs. The researchers were also aware that the majority of studies focused on developed destinations such as in Europe, Australia and New Zealand. While the tenants of sustainability apply universally, some local conditions required special consideration.

Of the academic publications, The Service Industry Journal presented a number of articles including "Sustainable Tourism: A View from Accommodation Businesses." paralleling the aim of this study (Hobson and Stephen, 2010). The article aimed at evaluating managerial attitudes, understanding and implementation of sustainable practices. Based on a review of previous studies, the article concluded that the term sustainability is not universally understood, and where it has been successfully adopted, it is more likely motivated by desire to cut costs rather than altruism or regulation. Results from their assessment reinforced an underlying proposed assumption for this study: "green practices are more likely to be adopted by larger hotels and those measures which deliver immediate cost savings (reducing energy consumption) are implemented more frequently than those which externalize benefits (buying from local suppliers, donating to environmental groups)". Greater support and oversight by both public and private infrastructure is presented as a means to ameliorate that hypothesized observation.

"Which Tourism Rules? Green Standards and GATS" supported this assertion. "Tourism certification relies to a great extent on government support...without such support two thirds of the schemes would not survive." The authors warned of the potential hazards of governments' preferential behavior towards green tourism enterprises. They concluded that without "a consensus on what is best practice for the setting, implementation, monitoring, certification and review of sustainable tourism standards" it would be impossible to "protect and enhance the role they play in sustainable development." Climpson (2008) echoed this concern by emphasizing the need for a network by which 
to contextualize individual and regional achievements and standards. Referring to the United Kingdom, sustainable destination management requires "a coherent set of national, regional and local policies is needed, linked to a national tourism strategy with clear targets."

Of the commercially sponsored sources consulted, Accor Hotel Group's Environmental Charter (2006) was comprehensive in the areas of focus and was one of the few sources to incorporate ISO- certification among its criteria. Ceres' Green Hotel Initiative Best Practices Survey (2010) was useful in terms of formatting and easiness of use as it gauged the depth of implementation on a gradual scale from 'well established' to 'no activity' and associated numerical scores. Eco-Green Hotels (2010) also made their checklist available on-line which was highly specific but provided only a yes or no option for responses. This might make quantitative analysis less illustrative. Eco-Green Hotels did however provided a presentation with a variety of hypothetical savings schemes. Green Lodging News (2010) provided a lengthy summary of various sustainable measures and associated links to websites where managers can find resources to implement these strategies.

In sum, there were no shortage of criteria and descriptions of sustainable management policies and practices however these criteria and descriptions tended to give equal weight to internalized benefits and externalities (i.e. certifications give equal weight to cost saving and altruistic behaviors when existing literature has established that the latter is neither cost effective nor widely adopted). Further, without a network or external source of motivation and regulations, businesses adopt these principles on a purely voluntary basis- such a system effectively excludes small or locally-owned enterprises without the economies-of-scale enjoyed by larger, multi-national hotels. Finally, without more cohesive international and regional networks and standards, legislating and assigning responsibility becomes challenging.

\section{Methodology}

In order to explore to what degree hotels in the capital city "Muscat" recognizes the environmental impacts of their economic choices, and to determine which of the numerous environmental considerations are most widely adopted. A survey was designed based on a number of previous studies about green tourism as well as brand-standards and green certification criteria to evaluate the levels of commitment and understanding of green hospitality management in the Capital City "Muscat". Questions were divided generally into five major categories of; (1) water usage; (2) energy management; (3) waste management; (4) staff awareness and training; (5) environment protection awareness; and (6) environmental management policy and implementation. Introductory demographic questions were also included at the beginning of the survey. Questions were adapted to fit local and industry considerations. For example, as no recycling program exists to date in the Muscat Municipality, related questions were omitted. It was worth noting that the lack of recycling facilities is not unique to Oman. Ellis (2008), in his review of the current situation of sustainable tourism in the United Kingdom cited that "recent interviews of hoteliers in the [UK] revealed several who had originally signed up to Visit Britain's Green Start program, only to withdraw because they don't have access to adequate waste collection or recycling facilities" It is also worth noting that in the desert climate of the Arabian Peninsula, hotels spend far more on cooling than heating, and water resources. Prior to final distribution, five samples of the survey were completed and reviewed for feed-back by faculty members and scholars in the department of tourism, the department of English, and the department of Geography at the College of Arts \& Social Sciences from Sultan Qaboos University. Due to research guidelines, only the final version with University approval was distributed publicly. Once a final draft was completed the survey was presented with a short introduction to familiarize the respondents with the aims of the study and provided contact information for any subsequent inquiries. The survey packet also included a letter of greeting in both English and Arabic from the University Administration.

Respondents were identified using the 2010 listing of hotels compiled by the Ministry of Tourism and ranked by class and location, publicly accessible on the Ministry official website as a free download. (MOT, 2010) Twenty-seven hotels were chosen ranging from 5-star to 3-star categories and included one hotel which had opened after the list was published and before stars were awarded. The selected hotels located within a 20 to 25 kilometer radius from down town the Capital City of Muscat. One exception was made for a 5-star resort located further from the study area (while still in the Municipality of Muscat) which provides a semiremote location as per its design. For simplicity, the first nine 3-star hotels were chosen from the downloaded list to reflect variability in size, type, and loca- 
tion of local hotels. In most cases the surveys were delivered to the general manager of the property to be completed by him or her. Except in those cases were the general manager was not available for the duration of this study or where the general manager was in charge of multiple properties. In the latter two cases, survey packets were delivered to Operations Managers for completion. Respondents were given two weeks from distribution to complete the survey and return it via fax.

To highlight some perspectives from policy makers and major tourism stakeholders in Oman about current sustainability trends and future goals regarding environmental management, results of the survey were compiled and analyzed and a set of summary statistics were presented to three individuals within the public, private and development sector seeking their comment and feedback. The interviews were unstructured as each individual represented diverse stakeholder interests and held unique qualifications. The interviews were framed around the premise that the research presented could be delivered in a way to inform policy makers and prompt discussion. All three individuals were asked how they would implement a greening policy in Oman, what challenges they would expect to encounter, and if possible, how to resolve them.

\section{Results and discussion}

In practice, due to an initially low level of response, the respondents were given one month to return the survey. Respondents were contacted through two rounds of follow-up calls conducted at week 2 and week 3 from the initial survey distribution. At the close of one month, a $50 \%$ response rate had been achieved. Twelve hotels returned the survey and one survey was returned incomplete. After several followups the completed form had yet to be returned so only relevant data were included.

Of the 12 surveys collected, three 5 -star hotels, five 4-star hotels, three 3-star, and one 2-star hotels responded to the survey. The reported target markets followed an expected break-down of heavy emphasis on business tourists which were subject to less seasonal fluctuation than the other categories. Two large 5 -star hotels were not represented despite repeated follow-ups. This omission should be noted as 5-star hotels account for the majority of revenue from the Capital City of Muscat hospitality industry. One keyinterview, conducted after the responses were collected indicated that resort and leisure tourists should have received a larger share of responses. However, as the time of the survey administration was near the end of the capital's tourist season, the discrepancy in results might reflect hotels shifting in market focus during the low season.

Survey results were compiled and scored based on numerical results. Point values were assigned based on the level of implementation indicated by the respondents. Scores were tallied and grouped by both type of hotel and category of questions. The responses categorized by hotel type were not necessarily a reliable metric for the study as the self-administered surveys resulted in very high levels of implementation regardless of stars. For instance, the 2-star hotels outperformed all other categories as seen in the table 1 below. As many green accreditation schemes being with a self-audit, the right-skewed distribution of results from this data is not unique and emphasizes the need for external audit and verification. Without follow-up and verification from each respondent, results should be treated with caution. The more telling data resulted from a compilation of thematic data. Through these aggregated scores, level of implementation can be seen and compared among a number of measures. Figure 1, 2, 3, 4, 5 \& 6 show the results by different environmental consideration targets. Staff and training initiatives resulted in the most implemented measure, and waste management was the least implemented. Energy management and water usage was the most divided initiative with $20 \%$ of respondents reporting no activity.

To highlight some perspectives from policy makers and major tourism stakeholders in Oman about current sustainability trends and future goals regarding environmental management, results of the survey were compiled and analyzed and a set of summary statistics were presented to three individuals within the public, private and development sector seeking their comment and feedback. The interviews were unstructured as each individual represented diverse stakeholder interests and held unique qualifications.

Table (1) Summary of Muscat Green Hotel Survey Results

\begin{tabular}{|c|c|}
\hline Hotels Surveyed & Mean Score \\
\hline 5-star : 3 & 77.7 \\
\hline 4-star: 5 & 69 \\
\hline 3-star: 3 & 76.2 \\
\hline 2-star: 1 & 78 \\
\hline Out of Possible 92 Points & 75.2175 \\
\hline Average Score $82 \%$ & \\
\hline
\end{tabular}


The interviews were framed around the premise that the research presented could be delivered in a way to inform policy makers and prompt discussion. All three individuals were asked how they would implement a greening policy in Oman, what challenges they would expect to encounter, and if possible, how to resolve them.

All those interviewed commented on the low response rate indicating that while, provocative, results should not be interpreted as entirely representative. They also remarked on the paucity of such research in the Gulf region and especially in Oman. It was also indicated that similar research should be conducted on a wider scale and involve some sort of auditing measures to verify the seemingly optimistic responses. All interviewees addressed the consistently underperforming waste management policy category. They also verified that there are few removal options, and little is known about the end-of pipe technologies implemented by recycling contractors as most use facilities located outside the country. Similarly, the researcher did not independently verify the claims made by each individual as in many cases policy information were not publicly available at the time of the interview.

The public sector interviewee represented the Omani Ministry of Tourism and provided commentary on policy development in the Sultanate. The interviewee confirmed that there is no official sustainable tourism or hospitality policy and all measures therein are currently voluntary; a policy is currently in development for implementation in the next, 8th 5-year plan. Such a policy is expected to be phased in, first among only 5-star hotels who would already be expected to be standard-bearers for sustainability due to Corporate Social Responsibility. It was unclear if such a policy would be voluntary or compulsory (both the private and development sector favored a compulsory policy). While other sub-sectors of tourism are included in the policy, the emphasis will be on hospitality. Two issues were raised by the public sector interviewee where attention should be given, the first of which concerns individual operations through voluntary self-audits and the Ministry-awarded star criteria which does not provide any provisions for environmental management. The current system needs improvement to provide sustainable future development through the inclusion of green standards in some form. The second issue concerns large projects where specific Corporate Social Responsibilities and environmental measures are written into the projects' design. Such measures also include the crucial components of follow-up and life-cycle planning. Generally, the Ministry looks to the private sector to drive environmental management policy creating an industry standard through broad implementation and competition for market share. A larger sustainability policy would encounter difficulty in implementing measures in the Sultanate's copious 2-star and 1-star hotels. Currently such measures are not an immediate concern, overshadowed by the need to impress the concepts of service quality and cleanliness.

The second interview was conducted with a representative of the private sector at the Al Bustan Palace Hotel, operated by Intercontinental Hotel Group (currently operated by the Ritz Carlton). Opened in 1985, the hotel closed for extensive renovation from 2007-2010. The major renovation incorporated many greening measures such as the installation of 1,700 energy efficient bulbs in the lobby's grand chandelier, the purchase of two state-of the-art efficiency boilers and the construction of a massive, grey water recycling plant for which it received recognition in National Geographic. The hotel has cultivated a relationship with the local community through bulk-purchases of handicrafts and local employment opportunities. Al Bustan has also partnered with various local organizations to support sustainability initiatives. Local demands on the hotel have forced the management to consider special needs.

The hotel's waste-management program, which is contracted to a Finnish company involves a natural compression process. The site's waste is collected and removed in cylinders although the interviewee could not verify what became of the tube once removed from the property. The interviewee has indicated that top-down measures from the public sector are needed to promote sustainability and education to overcome the perception problem among smaller hotels that green measures are costly. The greatest obstacle, as seen from the hospitality perspective is engaging the owner's interest in greening initiatives. Owners are often involved in multiple ventures where hotels can seek opportunities to make green partnerships. The owner must see and understand the benefits of greening initiatives to support them. There are a range of opportunities to incorporate greening programs into operations. The interviewee also stated that hotels can make use of monthly and annual efficiency reports, as well as future plans such as 3-5 year strategies. There is also a need for public and guest relations to educate consumers about measures taken at the hotel-level to promote sustainability. In 
a merging of cultural and sustainable tourism, the Al Bustan hotel offers guests the opportunity to collect a locally produced, traditional piece of jewelry upon check out if they re-use linens and towels. Overall, hotels in Muscat could benefit from more leadership from the Ministry of Tourism in terms of guidelines and policies recognizing that altruism may not suffice for the implementation of all environmental management policies.

The third interview was concluded with a representative from Omran, the Sultanate's publicly- owned development arm. Founded in 2005, Omran became operational in 2008 and since then has moved further from the Ministry of Tourism towards more autonomous operations. Omran exemplifies leading by example among the public sector. Omran is ISO 14000 registered and LEEDs certified and complies with 3rd party audits every 6 months to maintain affiliations. The company's office is decorated with posters promoting environmental awareness among its employees and visitors. Omran oversees Environmental Impact Assessments of its projects, permitting and compliance, as well as monitoring and reporting to the Ministry of Tourism. Omran develops compulsory sustainability policies for all projects under its supervision. Omran has implemented a range of sustainability programs in the three hotels which it operates. The major obstacles though, towards wider implementation remain a lack of waste management options, perceived high-cost of implementation, the subsidization of water and electricity, and the lack of incentive to reduce carbon footprints. Another major issue stressed was the absence of a strong voice for environmental protection in policy making. There is also a room for more leadership from the Ministry of Tourism in both regulation and promotion of sustainability efforts. Such a measure could be introduced by categorizing hotels and either green or conventional and offering incentives for guests to stay in the former. The Sultanate of Oman decrees development policy in a series of incremental Plans, dubbed 5-year plans. The latest plans have emphasized the diversification of the economy and has placed special attention on the expansion of the tourism sector.

\section{Conclusion}

The hospitality sector in Muscat is well positioned to embark on a sustainability campaign based on the interest indicated by stakeholders as well as the high level of awareness indicated by local hotels. However, to construct and implement a cohesive sustainability policy, greater cooperation will be required. Given the size and reach of the public sector in the Sultanate of Oman, greater leadership will be required through the use of incentives, application of both compulsory and voluntary standards as well as the promotion and branding of sustainability efforts and destinations. For the private sector, a greater effort to inform and educate guests about greening measures undertaken and alliances among green hotels to create an identifiable sustainable option for consumers will be necessary. The cooperation and involvement of environmental advocacy groups is key to developing a policy that will represent all stakeholders and break the current mold cast to reflect mostly operational concerns at the expense of larger issues of environmental impact. As a destination which distinguishes itself through its authenticity in all aspects, including an unspoiled environment, a sustainability policy is essential to ensuring the survival and growth of the destination and its natural beauty.

\section{Notes}

*Robyn Byrne was a visiting graduate research student from the US Fullbright Program, She conducted this study under the supervision of Dr. Mohamed Abdul-Ghani from the College of Arts and Social Sciences.

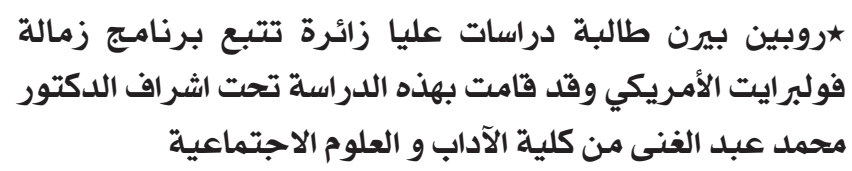

\section{References}

Accor Hotel Group's Environmental Charter. (2006). Sustainable Development : Earth Guest Program. Retrieved from http://www.accor.com/en/sustainabledevelopment/earth-guest-program/documents.html

Beioley, S. (1995). "Green tourism - soft or sustainable?", Insights 7, B75-89.

"CERES" Green Hotel Initiative: Best Practice Survey. (2010). Retrieved from http://www.ceres.org//Page. aspx?pid=761

Climpson, Anthony. (2008, March), "Sustainable Destination Management: the VICE Model." Tourism Insights February. Retrieved from http://www.insights. org.uk/articleitem.aspx?title=Sustainable+Destinatio n+Management\%3a+the+VICE+mode

Eco-Green Hotels. (2010, December). "Let's Make 
Your Hotel More Earth Friendly." Retrieved from http://www.ecogreenhotel.com/getting_started.php

Ellis, Jackie. (2008, September). "Sustainable Tourism: Where Are We Now?" Tourism Insights September. Retrieved from http://www.insights.org.uk/articleitem.aspx?title=Sustainable+Tourism\%3a+Where+ Are+We+Now\%3f

Hobson, Kim, and Stephen Essex. (2010). "Sustainable Tourism: A View from Accommodation Businesses." The Service Industries Journal 21.4. pp. 133-46.

Green Lodging News, (2010, December). "Research: Americans Prefer Single Seal for Green Product Certification. Retrieved from http://www.greenlodgingnews.com/research--americans-prefer-single-sealfor-green-product

MOT. (2010, November). "Mission and Objective"
Ministry of Tourism, Sultanate of Oman. Retrieved from http://www.omantourism.gov.om

OMRAN. (2010, November). "Our Beliefs" Retrieved from

http://www.omran.om/ourbeliefs.htm

Oman Airports. (2010). Retrieved from http://www.omanairports.com/seeb_newterminal. asp

Stabler, M. J., and Goodall, B. (1997). "Environmental Awareness, Action and Performance in the Guernsey Hospitality Sector." Tourism Management. 18.1 pp. 19-33.

WTTC. (2010). Travel \& Tourism Economic Impact: Oman 2010. Retrieved from http://www.wttc.org/ eng/Tourism_Research/Economic_Research/Country_Reports/Oman/

The Figures:

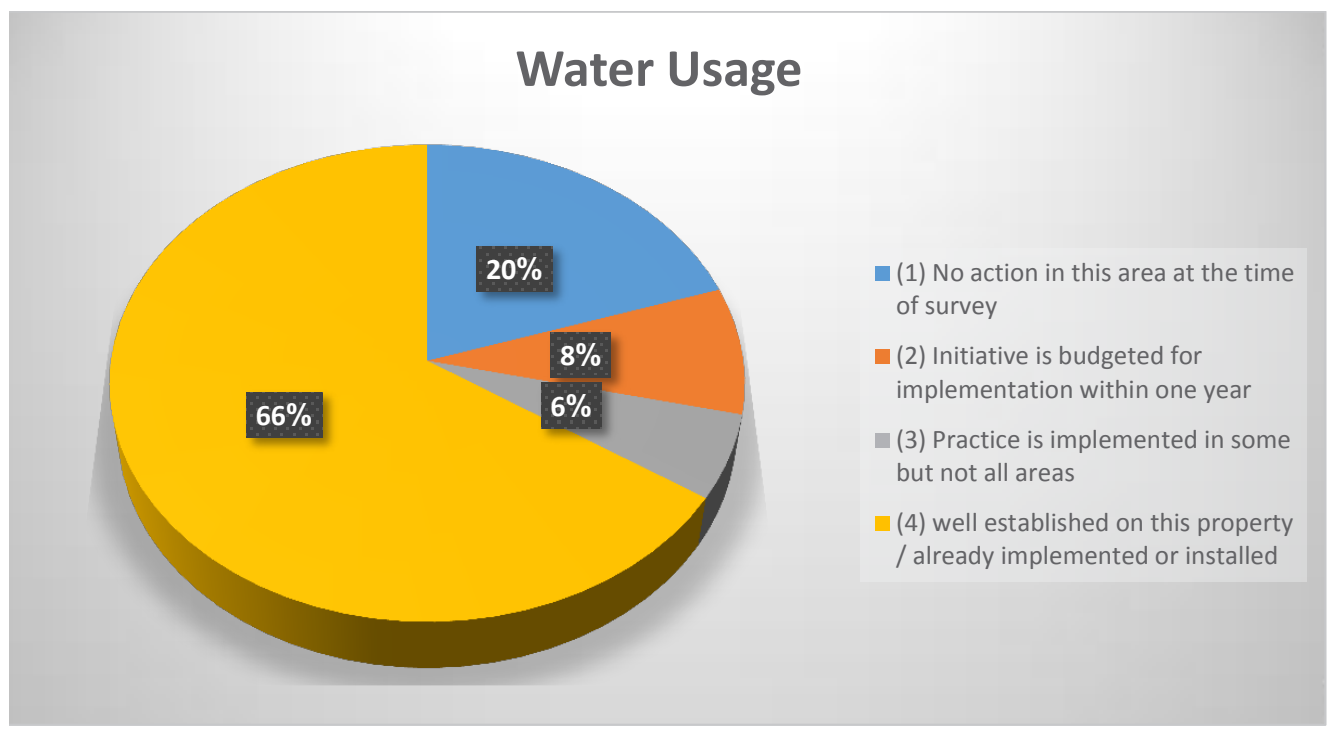

\begin{tabular}{|l|r|}
\hline \multicolumn{1}{|c|}{ Water Usage - 3 Questions } & \\
\hline (1) No action in this area at the time of survey & 7 \\
\hline (2) Initiative is budgeted for implementation within one year & 3 \\
\hline (3) Practice is implemented in some but not all areas & 2 \\
\hline (4) well established on this property / already implemented or installed & 23 \\
\hline
\end{tabular}

Figure 1 - Water Usage Practices 


\section{Energy Management}

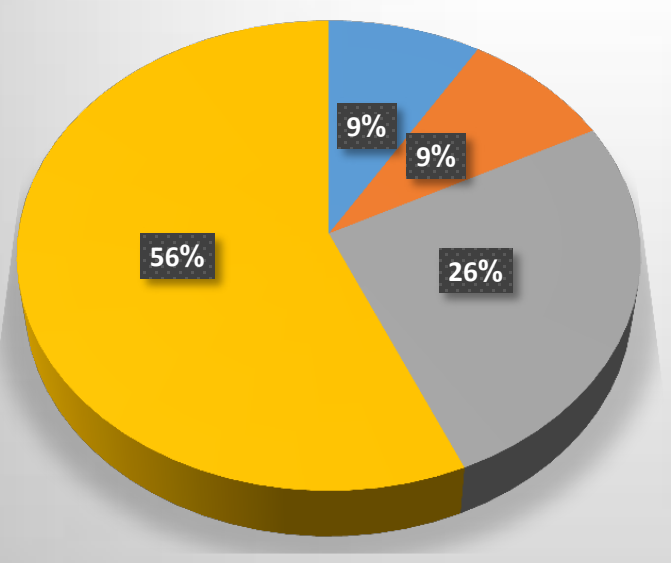

(1) No action in this area at the time of survey

(2) Initiative is budgeted for implementation within one year

(3) Practice is implemented in some but not all areas

(4) well established on this property / already implemented or installed

\begin{tabular}{|l|r|}
\hline \multicolumn{1}{|c|}{ Energy Management - 4 Questions } & \\
\hline (1) No action in this area at the time of survey & 4 \\
\hline (2) Initiative is budgeted for implementation within one year & 4 \\
\hline (3) Practice is implemented in some but not all areas & 12 \\
\hline (4) well established on this property / already implemented or installed & 26 \\
\hline
\end{tabular}

Figure 2 - Energy Management Practices

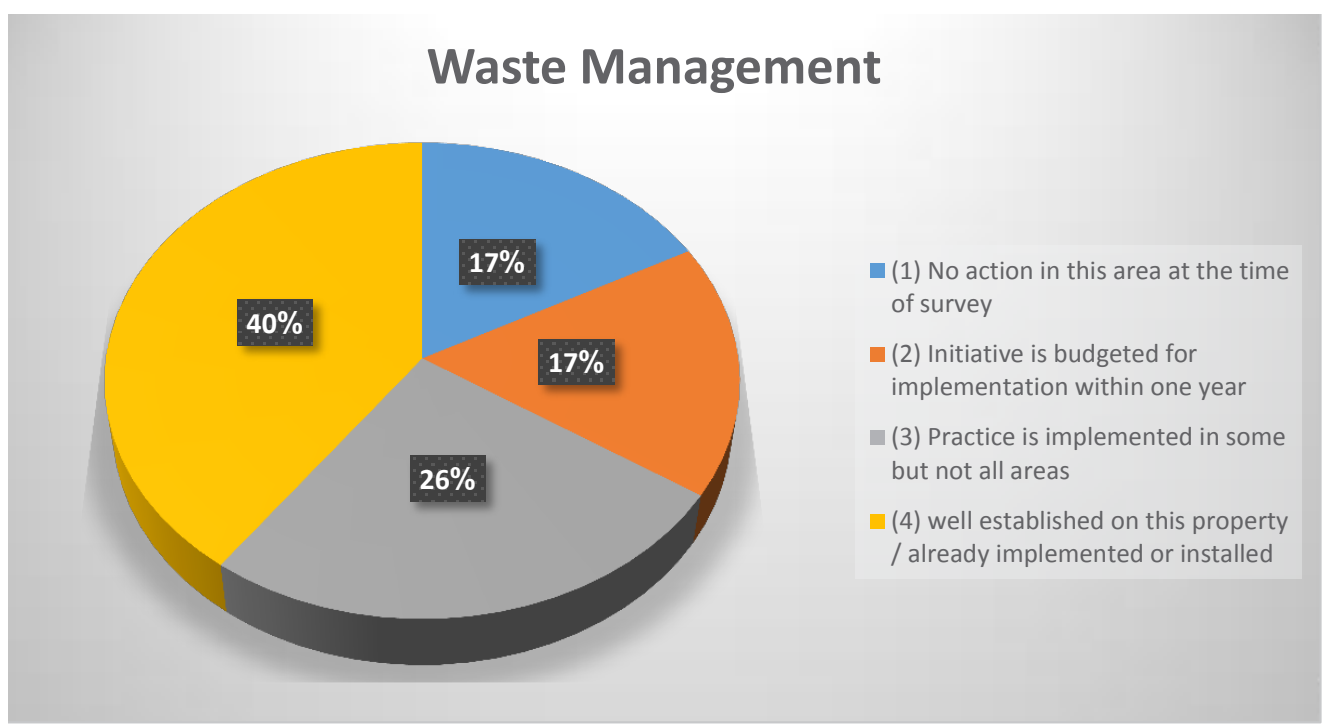

\begin{tabular}{|l|r|}
\hline \multicolumn{1}{|c|}{ Waste Management - 3 Questions } & \\
\hline (1) No action in this area at the time of survey & 6 \\
\hline (2) Initiative is budgeted for implementation within one year & 6 \\
\hline (3) Practice is implemented in some but not all areas & 9 \\
\hline (4) well established on this property / already implemented or installed & 14 \\
\hline
\end{tabular}




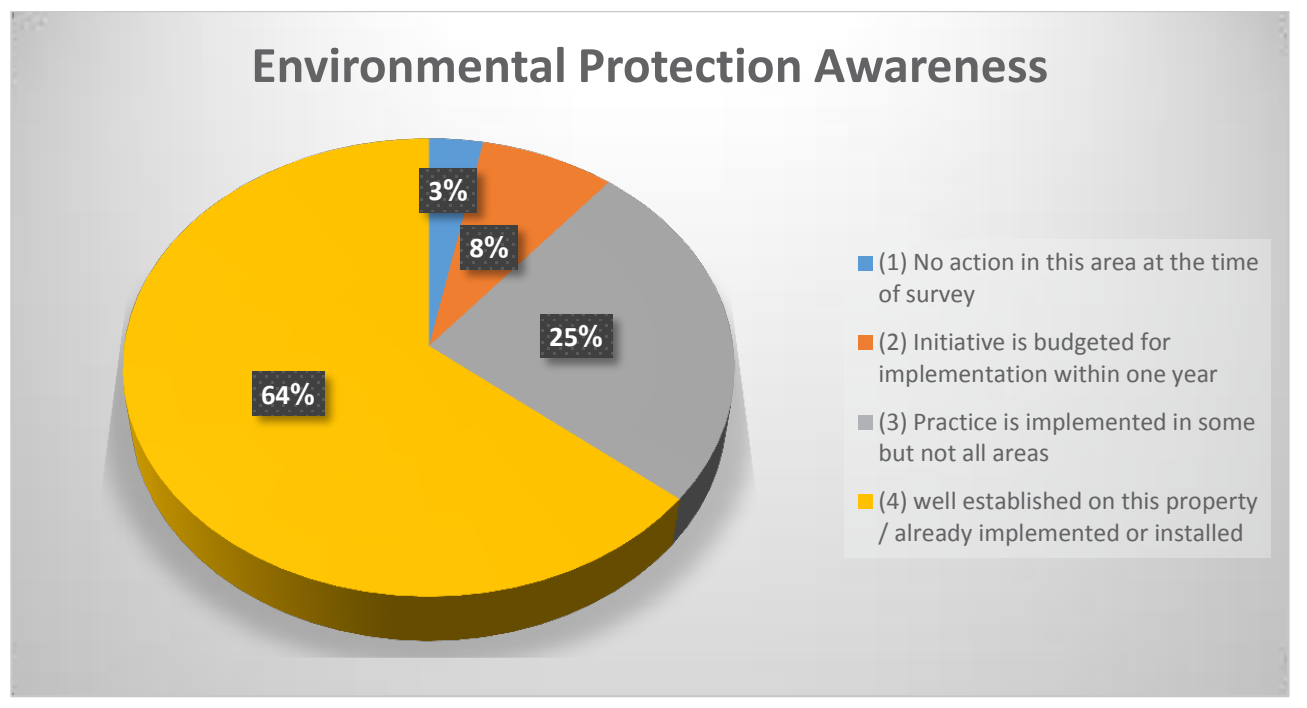

\begin{tabular}{|l|r|}
\hline \multicolumn{1}{|c|}{ Environmental Protection Awareness - 6 Questions } & \\
\hline (1) No action in this area at the time of survey & 2 \\
\hline (2) Initiative is budgeted for implementation within one year & 5 \\
\hline (3) Practice is implemented in some but not all areas & 16 \\
\hline (4) well established on this property / already implemented or installed & 41 \\
\hline
\end{tabular}

Figure 4 - Environmental Protection Awareness

\section{Staff Awareness \& Training}

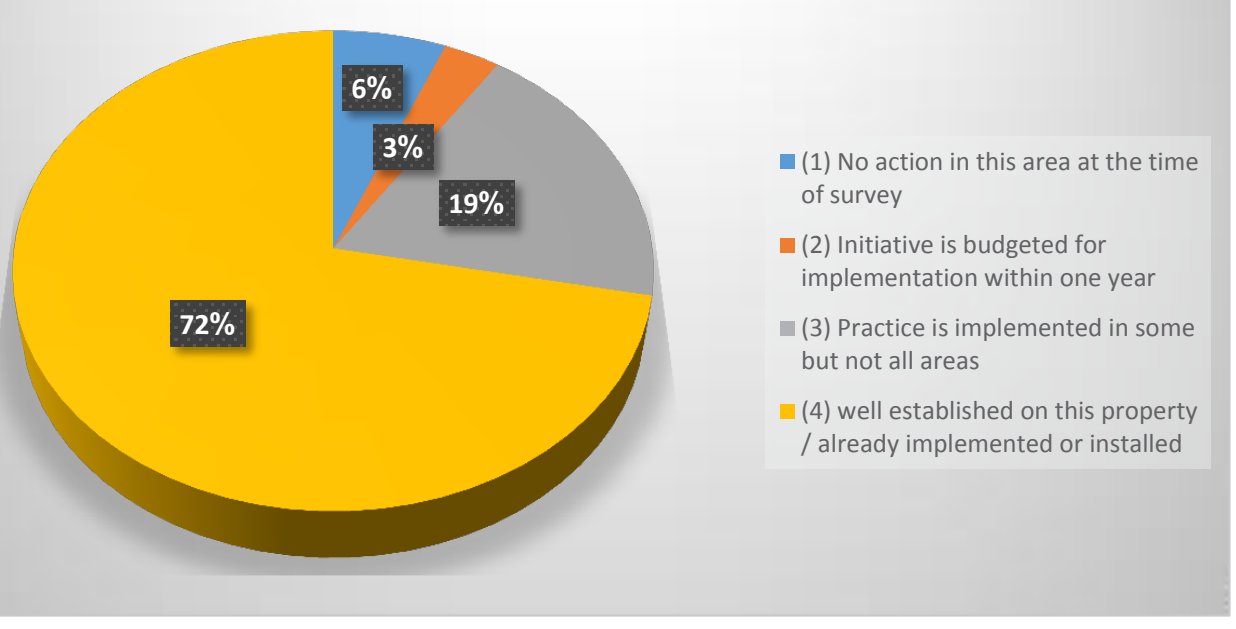

\begin{tabular}{|l|r|}
\hline \multicolumn{1}{|c|}{ Staff Awareness \& Training - 3 Questions } & \\
\hline (1) No action in this area at the time of survey & 2 \\
\hline (2) Initiative is budgeted for implementation within one year & 1 \\
\hline (3) Practice is implemented in some but not all areas & 6 \\
\hline (4) well established on this property / already implemented or installed & 23 \\
\hline
\end{tabular}




\section{Environmental Management Policy \& Implementation}

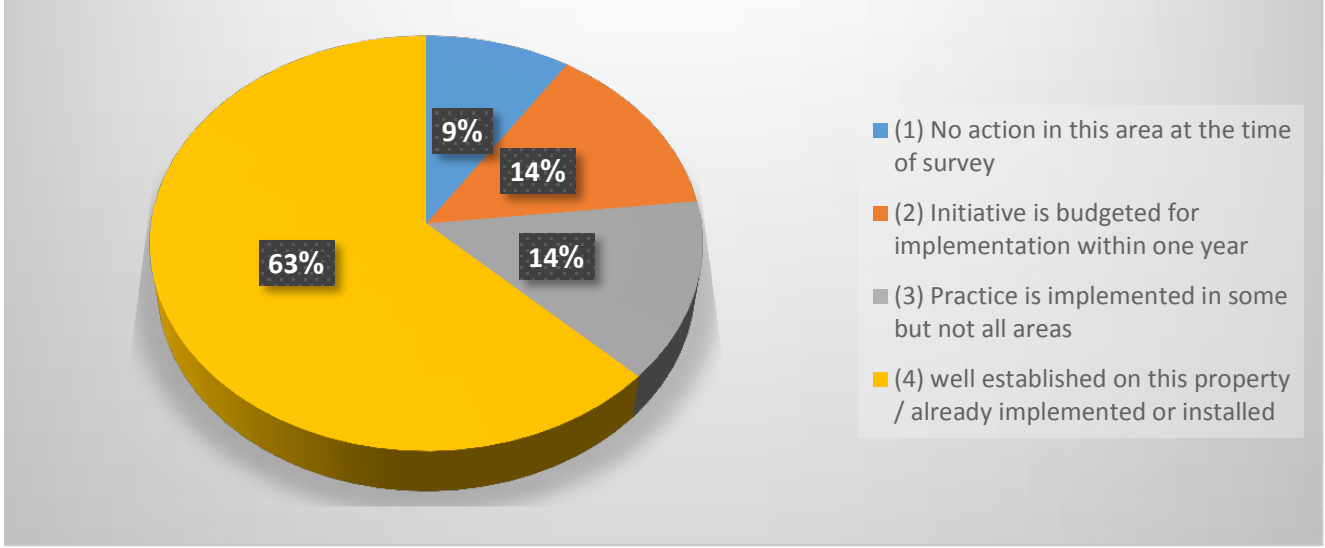

\begin{tabular}{|l|r|}
\hline \multicolumn{1}{|c|}{ Environmental Management Policy \& Implementation - 4 Questions } \\
\hline (1) No action in this area at the time of survey & 4 \\
\hline (2) Initiative is budgeted for implementation within one year & 6 \\
\hline (3) Practice is implemented in some but not all areas & 6 \\
\hline (4) well established on this property / already implemented or installed & 27 \\
\hline
\end{tabular}

Figure 6 - Environmental Management Policy \& Implementation 